\title{
Effect of Pit and Fissure Sealants on the Prevention of Enamel Demineralization After Exposure to Streptococcus mutans Biofilm: An In Vitro Study
}

\author{
Patrícia da Silva Lopes Pereira da Silva' Maristela Barbosa Portela Antônio Ferreira-Pereira² \\ Mônica Almeida Tostes ${ }^{1}$
}

\author{
'Department of Pediatric Dentistry, School of Dentistry, Universidade \\ Federal Fluminense, Niterói, RJ, Brazil \\ ${ }^{2}$ General Microbiology Department, Paulo de Góes Microbiology \\ Institute, Universidade Federal do Rio de Janeiro, Rio de Janeiro, \\ RJ, Brazil
}

\begin{abstract}
Address for correspondence: Patrícia da Silva Lopes Pereira da Silva, MSc, Universidade Federal Fluminense - Faculdade de Odontologia, Rua Mário Santos Braga, 28 Valonguinho, Niterói, 22020-140 RJ, Brazil

E-mail: patriciapereirasztm1@gmail.com
\end{abstract}

\begin{abstract}
Objective: The aim of this study was to evaluate the effect of sealants on the prevention of enamel demineralization and on biofilm metabolic activity.

Materials and Methods: Cavity preparations were performed on 45 blocks of bovine teeth ( $4 \times 4 \times 4$ mm) randomly assigned to three groups ( $n=15)$ : RI-Riva Light Cure ${ }^{\circledast} /$ SDI; EM-Embrace ${ }^{\mathrm{TM}}$ WetBond ${ }^{\mathrm{TM}}$ Pulpdent Corp. ${ }^{\oplus}$; and CO-Natural Flow/DFL resin (negative control). The sealed blocks were subjected to thermocycling (500 cycles/30 s). Half of the blocks were covered with acidresistant varnish to create a control area (RI, EM, and CO) and an experimental area (RI-EX, EM-EX, and CO-EX). They were subsequently exposed to Streptococcus mutans biofilm for assessment of demineralization by the Knoop microhardness test ( $50 \mathrm{~g} / 15$ $\mathrm{s})$, at $25,50,100,150$, and $200 \mu \mathrm{m}$ from the interface. In another test, the cylinders of the sealants ( $4 \mathrm{~mm} \times 3 \mathrm{~mm}$ ) were subjected to the biofilm metabolic activity test.

Results: The RI-EX group showed higher microhardness than CO-EX $(p<0.05)$ and less demineralization when compared to RI at all distances. Microbial activity was lower in EM compared to CO, but not statistically significant in relation to RI.

Conclusion: Both sealants can inhibit enamel demineralization in the presence of S. mutans biofilm.

Keywords: Dental enamel, dental resin, hardness test, glass ionomer cements
\end{abstract}

\section{Introduction}

Routine dental care is sought out to prevent caries and to arrest its progression.[1,2] Dental caries has a high prevalence in children and it is a public health problem.[3] The use of pit and fissure sealants has been well supported for preventing dental caries or arrest- ing its progression on occlusal surfaces of both permanent and primary teeth.[2,4,5] Fluoride release by sealant materials has been suggested to reduce the adhesion of $S$. mutans and may therefore contribute to caries prevention.[6-9] Previous studies have reported that fluoride level in Embrace WetBond (EWB) and glass ionomer showed higher fluoride release in water

How to cite this article: Pereira da Silva PSL, Portela MB, Ferreira-Pereira A, Tostes MA. Effect of Pit and Fissure Sealants on the Prevention of Enamel Demineralization After Exposure to Streptococcus mutans Biofilm: An In Vitro Study. J Pediatr Dent 2020;6(1):12-19 
and artificial saliva and had greater antimicrobial activity than did resin sealant.[10] Clinically, no difference was noted in the anticaries effect between ionomer and EWB sealants.[2,8] However, despite many comparative studies on resin sealant and ionomer material, only limited information is available on Riva Light Cure ${ }^{\oplus}$ and Embrace sealants applied on fissures. [2-15] Embrace sealants are biocompatible, do not contain bisphenol A, have hydrophilic properties, in addition to fluoride release, and have been indicated in pediatric dentistry.[10-16] Notwithstanding the anticaries efficacy of sealant treatment, the results remain inconsistent.

Accordingly, the present study evaluated the effect of an ionomer, Riva light Cure ${ }^{ø}$ sealant, and EWB on the prevention of enamel demineralization after $S$. mutans biofilm formation in vitro.

\section{Materials and Methods}

The samples were subjected to thermocycling, cariogenic biofilm formation, and Knoop microhardness test, and the cylinders of the sealants were subjected to a cariogenic biofilm metabolic activity test. The study design is shown in Fig. 1.

\section{Preparation of the specimens}

Sample size was calculated by establishing a statistical power of 0.95 and significance of 0.05 with effect size 1 . At least 13 specimens were necessary for each group. The bovine teeth were kept in a $10 \%$ formaldehyde solution until use. The teeth were polished at low speed with an Abbott-Robinson ${ }^{\circledR}$ bristle brush using pumice mixed with distilled water (Kavo Dental GmbH, Biberack, Germany) and analyzed thereafter under a stereoscopic magnifying glass (CGA 6745, Tecnival, Buenos Aires, Argentina). Only those teeth without cracks or macroscopic defects or any other enamel alterations were selected.

The crowns were separated from the roots with a double-sided diamond disc (Diamond wafering blades 1/2" diameter 4" x0.012" 7-ref 11-4244, Buehler Ltda, Lake Bluff, IL, USA). Buccal surfaces were separated using a water-cooled diamond-impregnated low-speed saw. An enamel block was obtained from each tooth. After embedding the blocks in acrylic resin, the buccal surfaces of the enamel specimens ( $4 \mathrm{mmx} 4 \mathrm{mmx} 4 \mathrm{~mm}$ ) were ground with $\mathrm{SiC}$ paper $(400,600$, and 1.200 grit sizes) to obtain flat surfaces. Each specimen was flattened and polished before cavity preparation. The 45 enamel blocks were therefore fixed with wax at the center of a crystal acrylic base $(30 \mathrm{~mm}$ in diameter and 8 $\mathrm{mm}$ in thickness), with the largest flat area of the enamel facing downwards. A 320-grit sandpaper (Carbimet Paper discs, Buehler, Lake Buff, IL, USA) was used under water cooling for dentin planing. The blocks were fixed with the embedded enamel surfaces so that they were visible, but they were flattened at low speed for 1 min using Politriz (Arotec, Cotia, SP, Brazil) and 600, 1000, and 1200-grit sandpapers (Extec Corp. Enfield, CT, USA) and for 2 min using a 2500-grit sandpaper (Extec Corp. Enfield, CT, USA). The whole sanding process was carried out manually and the samples were etched under minimum pressure to keep them on the sander plate.

\section{Cavity preparation}

A standardized cavity preparation was performed on the enamel of each block. The blocks were attached to acrylic bases in the central buccal region where a cavity was formed using a $2292 \mathrm{KG}$ Sorensen diamond drill (Barueri, SP, Brazil) at high speed under generous air/ water cooling. A "stop" mechanism was employed so that the cavity preparation pattern was maintained for every 10 teeth. After that, prophylaxis with pumice and water paste, application of $37 \%$ phosphoric acid for $30 \mathrm{~s}$, and washing with water for $60 \mathrm{~s}$ were performed. The restorations were performed according to the manufac-

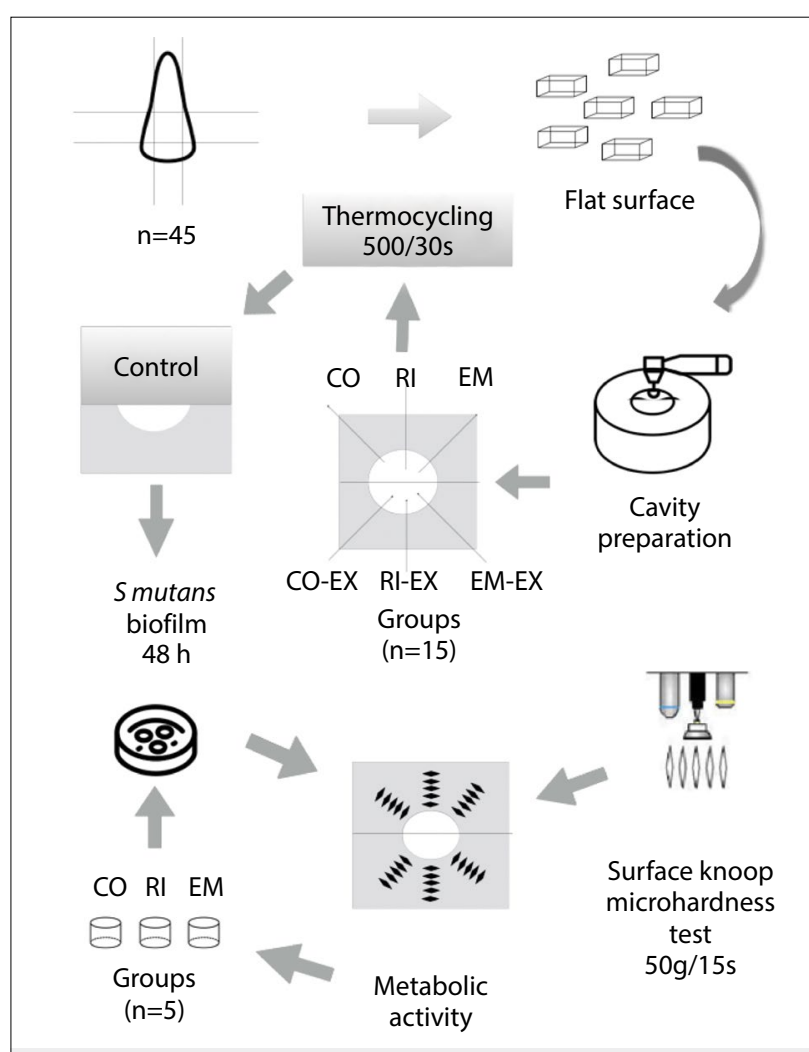

Figure 1. Schematic representation of the experimental design. 


\begin{tabular}{|c|c|c|c|c|c|c|c|c|c|c|c|c|c|c|c|c|c|c|c|}
\hline 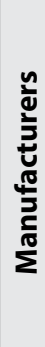 & & 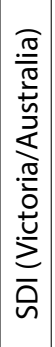 & & & & & & & 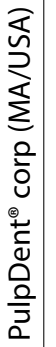 & & & & 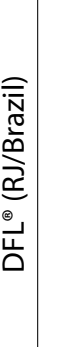 & & & & & & \\
\hline 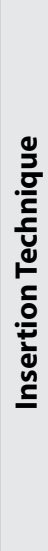 & 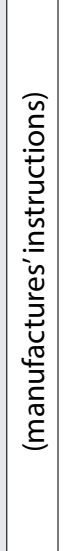 & 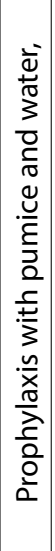 & 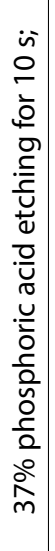 & 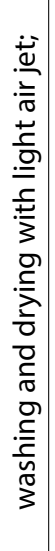 & 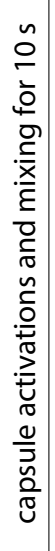 & & 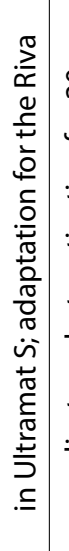 & 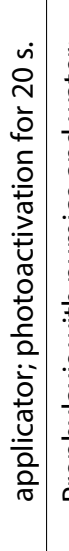 & 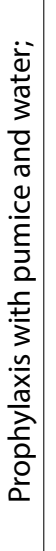 & 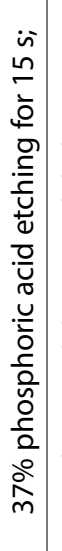 & 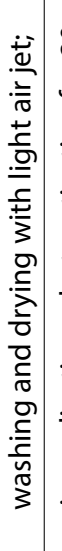 & 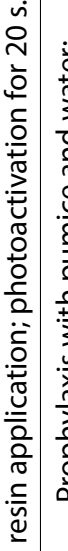 & 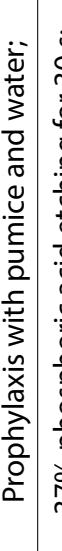 & 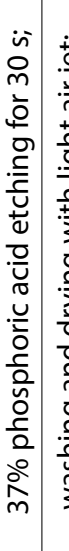 & 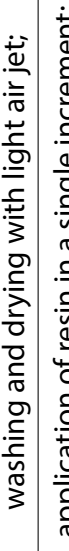 & 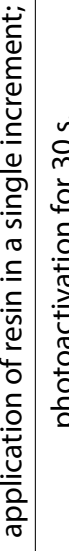 & & & \\
\hline 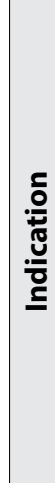 & & 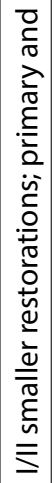 & 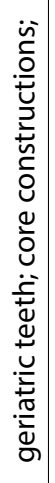 & 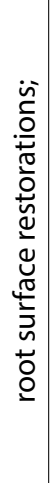 & 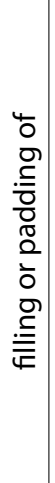 & 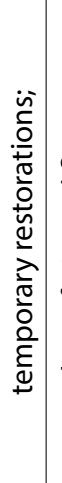 & 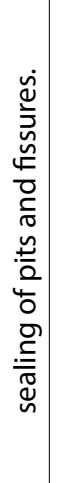 & & 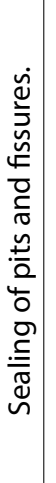 & & & & 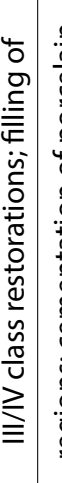 & 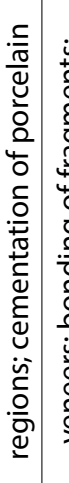 & 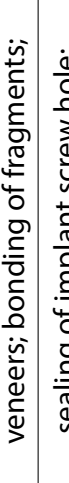 & 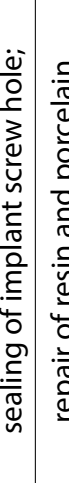 & 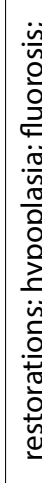 & 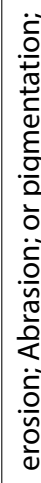 & 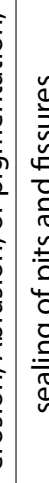 \\
\hline 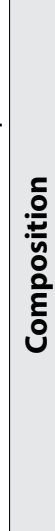 & & 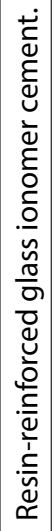 & 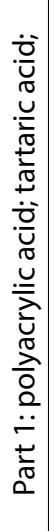 & 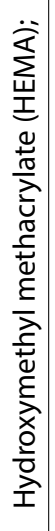 & 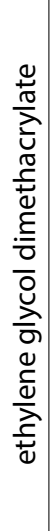 & 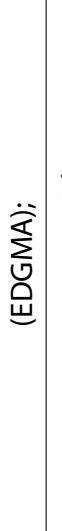 & 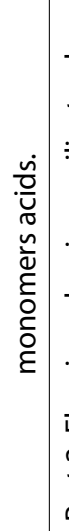 & 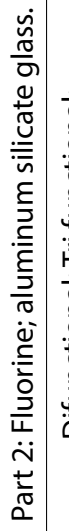 & 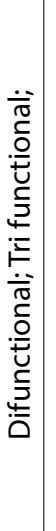 & 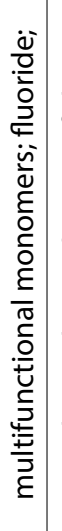 & 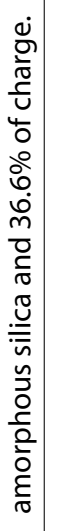 & & 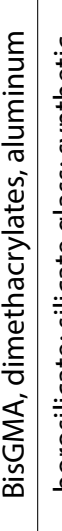 & 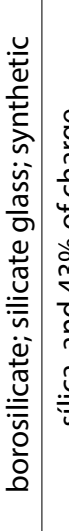 & 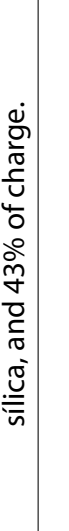 & & & & \\
\hline 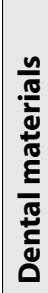 & & 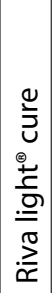 & & & & & & & 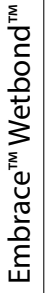 & & & & 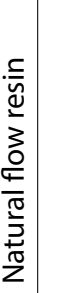 & & & & & & \\
\hline
\end{tabular}

turer's instructions (Table 1). The samples were polished with 3000grit sandpaper (3M, Maplewood, Minnesota, USA) and $1-\mu \mathrm{m}$ Alumina powder (Buehler, Lake Buff, IL, USA) and finally polished with felt disc (TEXMET C, ref. 40-1108, Buehler Ltda, Lake Buff, IL, USA) for $3 \mathrm{~min}$ at high speed until a glassy surface was obtained. At the end, the samples were observed under an optical microscope (Stemi 2000C, Zeiss, Jena, Germany) with a $10 \mathrm{X}$ objective until no material covered the tooth margin.

\section{Thermocycling procedure}

The samples were kept for $24 \mathrm{~h}$ in distilled water and placed in a thermocycler (Marconi, MA 470/3C, Piracicaba, SP, Brazil) at $5^{\circ} \mathrm{C}, 37^{\circ} \mathrm{C}$, and $55^{\circ} \mathrm{C}$ in 500 cycles of $30 \mathrm{~s}$ in each bath, considering a transfer time of $10 \mathrm{~s}$ between baths. The samples were subjected to $S$. mutans biofilm activity as described below.

\section{Induction of $S$. mutans biofilm formation}

The blocks were covered with two layers of acid-resistant enamel $\left(\right.$ Colorama $\left.^{\circledR}\right)$, except for half of the restored buccal surface (Fig. 1). No excess sealant had been observed at the preparation margin (optical microscope, 10x). Thus, half of the blocks, including enamel and sealant, were covered with acid-resistant varnish to create a control area (RI, EM, and CO) and an experimental area (RI-EX, EM-EX, and CO-EX), the latter of which was exposed to the biofilm.

In this phase, the samples were fixed in 45 wells (subdivided into 15 per group), in acrylic plates (TPP 24 ZellkulturTestplatte F, Trasadingen, Switzerland), and sterilized by ethylene oxide. The 
mature biofilm was formed by a cariogenic bacterium, Streptococcus mutans ATCC 25175 (American type culture collection, Fiocruz, Rio de Janeiro, RJ, Brazil) that had been previously grown for $24 \mathrm{~h}$ in a brain heart infusion broth (BHI, Difco, Sparks, MD, USA) at $37^{\circ} \mathrm{C}$ under microaerophilic conditions. The bacterial inoculum was adjusted to the 0.5 McFarland standard. Subsequently, this bacterial suspension was diluted 1:100 and $10 \mu \mathrm{L}$ was inoculated in each well with BHI supplemented with $2 \%$ sucrose. The plates were then incubated at $37^{\circ} \mathrm{C}$ under microaerophilic conditions for $48 \mathrm{~h}$. The growth medium was renewed every $24 \mathrm{~h}$.

\section{Knoop microhardness test}

The samples were positioned parallel to the coordinated table and adjusted to set the focus. Two rows of five indentations were performed with a Knoop indenter (HMV-G $21^{\text {st }}$, Shimada Microdurometer Corp., Japan) using a force of $0.05 \mathrm{HK}(50 \mathrm{~g}$ or $490.3 \mathrm{mM})$ and an indentation time of $15 \mathrm{~s}$ (Fig. 1). The first indentation was performed at $25 \mu \mathrm{m}$ from the interface and the other indentations kept a distance of $50 \mu \mathrm{m}$ between them. The test was then performed. The same procedure was repeated for the control area after removing the acidresistant varnish.

\section{Analysis of the microbial metabolic activity}

Microbial metabolic activity was measured by a colorimetric assay, which verified the enzymatic reduction reaction of the thiazolyl blue tetrazolium bromide (MTT, Sigma Aldrich, Sr. Louis, MO, USA) by $S$. mutans viable cells from the formed biofilm. The cylindrical samples (measuring $4 \mathrm{~mm}$ in diameter and $3 \mathrm{~mm}$ in thickness) were carefully prepared by dispensing the material in a standardized acrylic matrix. The insertion of the material and photopolymerization followed the manufacturers' recommendation, as described in Table 1 . These specimens $(n=5)$ were transferred to cell culture plates ( 24 well plates) for the induction of $S$. mutans biofilm growth. $S$. mutans biofilm was induced according to the previously described methodology.

After $48 \mathrm{~h}$ of biofilm formation, the samples were carefully transferred to other sterile plates and $500 \mu \mathrm{L}$ of MTT ( $1 \mathrm{mg} / \mathrm{mL}$ in PBS) was added to each well and the plates were then incubated at $37^{\circ} \mathrm{C}$ under microaerophilic conditions for $1 \mathrm{~h}$ in the absence of light. Subsequently, $500 \mu \mathrm{L}$ of dimethyl sulfoxide (DMSO) was added to each well and the plates were gently mixed and incubated for another $20 \mathrm{~min}$ in the absence of light. The solutions were transferred to other plates and placed in a microplate reader at a wavelength of $540 \mathrm{~nm}$. Higher absorbance indicates a higher metabolic activity of biofilm-forming cells.

\section{Statistical analysis}

The data were analyzed by GraphPad Prism, version 8.0 (GraphPad Software, Inc., USA). All data were initially verified using the Shapiro-Wilk test. Based on these preliminary analyses, the Knoop microhardness test data were subjected to the Kruskal-Wallis and MannWhitney tests. The control of Knoop microhardness after exposure to biofilm in the same groups was analyzed using Wilcoxon's test.

All analyses were performed at a significance level of 0.05 Fig. 2 prepared by GraphPad Prism, version 8.0, presents the results for hardness and the coefficient of variation in the groups at different distances. The medians, minimum and maximum values, and coefficient of variation of the metabolic activity test results obtained for the $S$. mutans biofilm formed on the materials after $48 \mathrm{~h}$ are shown in Table 2.

\section{Results}

\section{Knoop microhardness test}

The average Knoop microhardness values and confidence interval for the marginal seal at different distances are shown in Fig. 2. Smaller values are observed for the enamel margins subjected to the biofilm when compared to the corresponding control. There was loss of hardness in all groups subjected to the cariogenic biofilm; however, this difference was not significant in the RI-EX group when compared to the RI control (paired Wilcoxon's test; $\mathrm{p}>0.05$ ). Regarding the extent of demineralization, a statistically significant difference was observed only at a distance of $25 \mathrm{~m}$ from the enam$\mathrm{el} /$ material margin in the areas exposed to $S$. mutans biofilm in all groups. At this distance, the RI-EX group showed the highest Knoop microhardness value compared to the CO-EX and EM-EX groups (KruskalWallis; Mann-Whitney; $\mathrm{p}<0.05$ ).

Table 2. Metabolic activity of S. mutans biofilm formed on the materials after $48 \mathrm{~h}$

\begin{tabular}{|l|c|c|c|}
\hline & CO & EM & RI \\
\hline Median & $0.061^{\mathrm{b}}$ & $0.049^{\mathrm{a}}$ & $0.055^{\mathrm{a}}$ \\
\hline $\begin{array}{l}\text { Minimum- } \\
\text { maximum }\end{array}$ & $0.059-0.065$ & $0.040-0.052$ & $0.053-0.061$ \\
\hline $\begin{array}{l}\text { Coefficient of } \\
\text { variation }\end{array}$ & $4.95 \%$ & $13.29 \%$ & $7.39 \%$ \\
\hline
\end{tabular}

Different letters indicate significant difference $(p<0.05)$. 


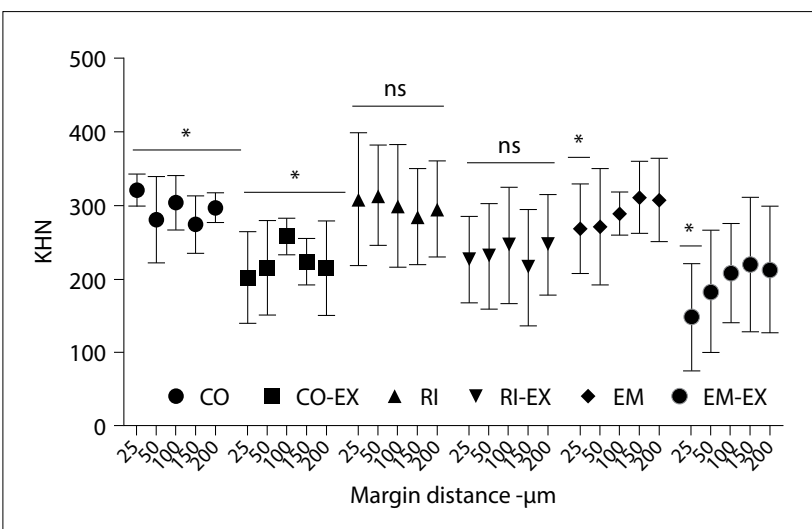

Figure 2. Mean hardness and coefficient of variation in the groups at different distances. $\left(^{*}\right)$ means statistical difference in the group, considering the control and experimental areas (exposed to $S$. mutans biofilm) at the referred distances.

\section{Analysis of microbial metabolic activity}

All materials showed accumulation of $S$. mutans biofilm after $48 \mathrm{~h}$. The EM group showed a statistically significant difference when compared to the CO group; however, there was no statistically significant difference when compared to the RI group (Table 2).

\section{Discussion}

The present in vitro study evaluated the influence of two fluoride-releasing materials used in pit and fissure sealants for the prevention of enamel demineralization by $S$. mutans biofilm. Knoop microhardness and metabolic activity tests were used for the analysis. Several studies have used different methodologies to compare the application of ionomeric and resinous materials to pits and fissures in an attempt to prevent demineralization.[17,20-22] Therefore, in this study, a cavity preparation was performed to simulate the conditions of pits and fissures and the Knoop microhardness test was carried out to assess demineralization around the preparation margins after 48 -hour biofilm formation. Knoop microhardness has been widely used for this purpose[18,23,24] and the $S$. mutans biofilm metabolic activity test, which can simulate oral conditions, has been used to replace cyclic $\mathrm{pH}$.[22] Bovine teeth were used in this study. Human teeth are better at mimicking the effects of demineralization but obtaining the ideal number of teeth with a surface that is large enough to explore would pose a great challenge. Both histological and morphological similarities led to the choice of bovine teeth which, due to their large size and availability, allowed widely exploring the same enamel block, if necessary. Accordingly, bovine teeth are widely used in dental research.[25-27]
The antimicrobial activity and remineralization associated with the presence of fluoride-releasing sealants are widely acknowledged in laboratory and clinical studies. $[4,18,28,29]$ Retention in and penetration into pits and fissures, risk of isolated carious lesions, and the inherent properties of the materials are some of the factors that can affect the effectiveness of a sealant. $[19,20,21]$

In the present study, fluoride-releasing materials interfered with the metabolic activity of the biofilm, confirming the antimicrobial activity of fluoride.[24] The model used in this study for prevention of demineralization might have contributed to the results found for the dental materials tested. Although both fluoridereleasing materials could prevent demineralization, the RI group showed better results as it interfered with the demineralization process at the tooth/material interface compared to the other material tested, and was therefore compatible with the performance of ionomeric materials described in other studies.[18,23] These results can be explained by the quick effect of fluoridereleasing ionomeric materials within the first hours, acting initially at the tooth/material interface and remaining constant at lower concentrations. [30] In addition, prevention of demineralization occurred after aging of the material. Aging by thermocycling, as used in this study, might have contributed to lower bacterial adhesion. According to Bürgers et al [29] aging can increase the material's roughness but decrease free surface energy. The decrease in surface energy influences bacterial adhesion. Bürgers et al [29] found lower bacterial adhesion in several resinous and ionomeric materials, but they did not evaluate changes in enamel caused by the decrease in surface energy.

The results in this study corroborate those obtained by Amaral et al [18] in their in situ study, which showed greater remineralization efficiency in fissures treated with ionomeric sealant when compared to resinous materials without fluoride release. There were dentin carious lesions in $7.8 \%$ and $6.7 \%$ of teeth treated with glass ionomer cements and EWB, respectively.[31] Therefore, no statistical differences were observed in retention rates in any of the groups.[31] Note that, in the present study, enamel microhardness around materials was measured after a $48 \mathrm{~h}$ exposure to cariogenic challenge ( $S$. mutans biofilm with culture medium supplemented with sucrose). The cariogenic effects tend to persist for a long time, as also demonstrated by the in vivo studies described above. EM has previously shown greater $S$. mutans inhibition compared to other fluoride-releasing materials and still maintained inhibitory 
capacity for a long time.[32] In that same study, greater inhibitory capacity was obtained in sampled materials and not when associated with enamel.[32] Similar results were found in the present study. Thus, EM showed microbial inhibition when the material was tested immediately, but fluoride release could not be maintained after aging.

Regarding the accumulation of $S$. mutans biofilm on the surface of the materials, the CO group showed higher accumulation, whereas the EM group showed lower biofilm formation compared with the RI group, but there was no statistical difference between them. This may have probably occurred because of the larger fluoride release in the EM group. A large amount of fluoride was released in the first few hours, decreasing over time, possibly because of the closed polymer matrix formed after photopolymerization.[10]

On the other hand, glass ionomer cement maintained constant fluoride release for a long time.[10] Besides, EM also showed higher antimicrobial activity than other sealants with lower fluoride release.[10] This suggests that fluoride release may have been a relevant factor in the present study. In addition to the presence of fluoride, other factors can influence biofilm formation on the material's surface, such as surface roughness, chemical composition, and particle size,[33] but these factors were not tested in the present study.

Metabolic activity of S mutans biofilm viable cells was quantitatively and indirectly measured on a spectrophotometer after the addition of MTT, which allows enzymatic reaction and changes the color of the medium. Even though this method does not quantify biofilm accumulation thoroughly (considering cell formation and extracellular matrix), it is widely used in several studies.[34-36]

This study has some limitations. The metabolic activity test assessed only $S$. mutans biofilm, which does not represent biofilm present in the oral cavity. Therefore, our results cannot be extended to clinical situations without some restrictions. [29] Furthermore, the Knoop microhardness test is a widely used indirect method for evaluating demineralization, but other methods can be used for the same purpose.[18,37-39] Evaluating the subsurface lesion formed could provide greater knowledge about the influence of these materials on the remineralization process or demineralization inhibition.

Interestingly, both fluoride-releasing materials were able to prevent demineralization even after the material was "aged" through the thermocycling process. Our study did not evaluate demineralization immediately after placement of the material, as in other studies. $[17,39]$

\section{Conclusion}

Our findings, albeit limited, show prevention occurred after the initial period of largest fluoride release. This underscores the importance of the aging process to interpret in vivo results.

In other words, the glass ionomer modified by resin has not been compared or evaluated in any other study regarding its ability to prevent caries, making comparisons between results impossible. Many studies have been carried out since the introduction of glass ionomers as pit and fissure sealants and their effectiveness has been questioned because of their low retention. In studies with resin-reinforced glass ionomer, better retention has been observed with fluoride release, but effectiveness is still unclear. The fluoride "refill" capacity from glass ionomer has been well known as a clinical advantage of the material, but this should be further investigated in future studies. Analyzing the results obtained for Knoop microhardness, metabolic activity tests demonstrated a greater ability to prevent demineralization in the enamel adjacent to the material in the RI group when compared to $\mathrm{CO}$ and EM groups. This prevention occurred close to the tooth/ material interface at about $25 \mu \mathrm{m}$. Both fluoride-releasing dental materials (RI and EM) showed an inhibitory capacity against the metabolic activity of the cariogenic biofilm tested.

\section{Conflict of Interest: None declared.}

\section{References}

1. Olatosi OO, Onyejaka NK, Oyapero A, Ashaolu JF, Abe A. Age and reasons for first dental visit among children in Lagos, Nigeria. Niger Postgrad Med J 2019;26(3):158-163

2. Marthur VP, Dhillon JK. Dental Caries: A disease which needs attention. Indian J Pediatric 2018;85(3):202-206

3. Fontana M, Gonzalez-Cabezas C. Evidence-based dentistry caries risk assessment and disease management. Dent Clin North Am 2019;63(11):119-128

4. Sreedevi A, Mohamed S. Sealants, pit and fissure. In: StatPearls. Treasure Island (FL): StatPearls Publishing. 2020

5. Pollick $\mathrm{H}$. The role of fluoride in the prevention of tooth decay. Pediatric Clin North Am 2018;65(5):923-940

6. Cvikl B, Moritz A, Bekes K. Pit and fissure sealants-A comprehensive review. Dent J (Basel) 2018;6(2):18 doi:10.3390/ dj6020018

7. Carvalho JC, Dige I, Machiulskiene V, et al. Occlusal caries: Biological approach for its diagnosis and management. Caries Res 2016;50(6):527-542 doi:10.1159/000448662 
8. Welbury R, Raadal M, Lygidakis NA; European Academy of Paediatric Dentistry. EAPD guidelines for the use of pit and fissure sealants. Eur J Paediatr Dent 2004;5(3):179-184

9. Colombo S, Beretta M. Dental Sealants Part 3: Which material? Efficiency and effectiveness. Eur J Paediatr Dent 2018;19(3):247249 doi:10.23804/ejpd.2018.19.03.15

10. Fiorati-Aguiar SM, Lucisano MP, Silva LABD, et al. Mechanical, chemical and antimicrobial properties of a bisphenol A-free pitand-fissure sealant. Am J Dent 2018;31(6):279-284

11. Panigrahi A, Srilatha KT, Panigrahi RG, Mohanty S, Bhuyan SK, Bardhan D. Microtensile bond strength of embrace wetbond hydrophilic sealant in different moisture contamination: An in-vitro study. J Clin Diagn Res 2015;9(7):ZC23-ZC25 doi:10.7860/JCDR/2015/11662.6178

12. Arrow P, Riordan PJ. Retention and caries preventive effects of a GIC and a resin-based fissure sealant. Community Dent Oral Epidemiol 1995;23(5):282-285 doi:10.1111/j.1600-0528.1995. tb00249.x

13. Haznedaroğlu E, Güner Ş, Duman C, Menteş A. A 48-month randomized controlled trial of caries prevention effect of a one-time application of glass ionomer sealant versus resin sealant. Dent Mater J 2016;35(3):532-538 doi:10.4012/dmj.2016-084

14. Mickenautsch S, Mount G, Yengopal V. Therapeutic effect of glass ionomers: an overview of evidence. Aust Dent J 2011;56(1):10103 doi:10.1111/j.1834-7819.2010.01304.x

15. Ngo H, Opsahl-Vital S. Minimal intervention dentistry II: part 7. Minimal intervention in cariology: the role of glass-ionomer cements in the preservation of tooth structures against caries. $\mathrm{Br}$ Dent J 2014;216(10):561-565 doi:10.1038/sj.bdj.2014.398

16. Berg JH, Croll TP. Glass ionomer restorative cement systems: an update. Pediatr Dent 2015;37(2):116-124

17. Khalili Sadrabad Z, Safari E, Alavi M, Shadkar MM, Hosseini Naghavi SH. Effect of a fluoride-releasing fissure sealant and a conventional fissure sealant on inhibition of primary carious lesions with or without exposure to fluoride-containing toothpaste. J Dent Res Dent Clin Dent Prospects 2019;13(2):147-152 doi:10.15171/joddd. 2019.023

18. Amaral MT, Guedes-Pinto AC, Chevitarese O. Effects of a glass-ionomer cement on the remineralization of occlusal caries-an in situ study. Braz Oral Res 2006;20(2):91-96 doi:10.1590/ s1806-83242006000200001

19. Liu W, Xiong L, Li J, Guo C, Fan W, Huang S. The anticaries effects of pit and fissure sealant in the first permanent molars of school-age children from Guangzhou: a population-based cohort study. BMC Oral Health 2019;19(1):156 doi:10.1186/s12903-0190846-x

20. Ghasemi A, Torabzadeh H, Mahdian M, Afkar M, Fazeli A, Akbarzadeh Baghban A. Effect of bonding application time on the microleakage of Class V sandwich restorations. Aust Dent J 2012;57(3):334-338 doi:10.1111/j.1834-7819.2012.01712.x

21. Hepdeniz OK, Temel UB, Ugurlu M, Koskan O. The effect of surface sealants with different filler content on microleakage of Class V resin composite restorations. Eur J Dent 2016;10(2):163169 doi: $10.4103 / 1305-7456.178315$
22. Subramaniam P, Konde S, Mandanna DK. Retention of a resin-based sealant and a glass ionomer used as a fissure sealant: a comparative clinical study. J Indian Soc Pedod Prev Dent 2008;26(3):114-120 doi:10.4103/0970-4388.43192

23. Maia AC, Mangabeira A, Vieira R, et al. Experimental composites containing quaternary ammonium methacrylates reduce demineralization at enamel-restoration margins after cariogenic challenge. Dent Mater 2019;35(8):e175-e183 doi:10.1016/j.dental.2019.05.021

24. Oliveira MRC, Oliveira PHC, Oliveira LHC, et al. Microhardness of bovine enamel after different fluoride application protocols. Dent Mater J 2019;38(1):61-67 doi:10.4012/dmj.2017-399

25. Panariello BH, Azabi AA, Mokeem LS, et al. The effects of charcoal dentifrices on Streptococcus mutans biofilm development and enamel demineralization. Am J Dent 2020;33(1):12-16

26. Ma L, Chen J, Han $\mathrm{H}$, et al. Effects of lemon essential oil and limonene on the progress of early caries: An in vitro study. Arch Oral Biol. 2020;111:104638 doi:10.1016/j.archoralbio.2019.104638

27. Fan $M$, Zhang $M, X u H H K$, et al. Remineralization effectiveness of the PAMAM dendrimer with different terminal groups on artificial initial enamel caries in vitro. Dent Mater 2020;36(2):210-220 doi:10.1016/j.dental.2019.11.015

28. Sundfeld D, Machado LS, Franco LM, et al. Clinical/Photographic/ Scanning electron microscopy analysis of pit and fissure sealants after 22 years: A case series. Oper Dent 2017;42(1):10-18 doi:10.2341/15-237-C

29. Bürgers R, Cariaga T, Müller R, et al. Effects of aging on surface properties and adhesion of Streptococcus mutans on various fissure sealants. Clin Oral Investig 2009;13(4):419-426 doi:10.1007/ s00784-009-0256-6

30. Salmerón-Valdés EN, Scougall-Vilchis RJ, Alanis-Tavira J, Morales-Luckie RA. Comparative study of fluoride released and recharged from conventional pit and fissure sealants versus surface prereacted glass ionomer technology. J Conserv Dent 2016;19(1):41-45 doi:10.4103/0972-0707.173197

31. Haricharan PB, Barad N, Patil CR, Voruganti S, Mudrakola DP, Turagam N. Dawn of a new age fissure sealant? A study evaluating the clinical performance of embrace WetBond and ART sealants: results from a randomized controlled clinical trial. Eur J Dent 2019;13(4):503-509 doi:10.1055/s-0039-1696894

32. Naorungroj S, Wei HH, Arnold RR, Swift EJ Jr, Walter R. Antibacterial surface properties of fluoride-containing resin-based sealants. J Dent 2010;38(5):387-391 doi:10.1016/j. jdent.2010.01.005

33. Cazzaniga G, Ottobelli $\mathrm{M}$, Ionescu AC, et al. In vitro biofilm formation on resin-based composites after different finishing and polishing procedures. J Dent 2017;67:43-52 doi:10.1016/j. jdent.2017.07.012

34. Vidal ML, Rego GF, Viana GM, et al. Physical and chemical properties of model composites containing quaternary ammonium methacrylates. Dent Mater 2018;34(1):143-151 doi:10.1016/j. dental.2017.09.020 
35. Oliveira PRA, Coutinho TCL, Portela MB, Paula VCA, Tostes MA. Influence of biofilm formation on the mechanical properties of enamel after treatment with CPP-ACP crème. Braz Oral Res 2017;31:e84 doi:10.1590/1807-3107BOR-2017.vol31.0084

36. Campos KPL, Viana GM, Cabral LM, et al. Self-cured resin modified by quaternary ammonium methacrylates and chlorhexidine: Cytotoxicity, antimicrobial, physical, and mechanical properties. Dent Mater 2020;36(1):68-75 doi:10.1016/j.dental.2019.10.007

37. Pires PM, Santos TPD, Fonseca-Gonçalves A, Pithon MM, Lopes RT, Neves AA. A dual energy micro-CT methodology for vis- ualization and quantification of biofilm formation and dentin demineralization. Arch Oral Biol 2018;85:10-15 doi:10.1016/j. archoralbio.2017.09.034

38. Alkattan R, Lippert F, Tang Q, Eckert GJ, Ando M. The influence of hardness and chemical composition on enamel demineralization and subsequent remineralization. J Dent 2018;75:34-40 doi:10.1016/j.jdent.2018.05.002

39. Díaz-Garrido N, Lozano C, Giacaman RA. Frequency of sucrose exposure on the cariogenicity of a biofilm-caries model. Eur J Dent 2016;10(3):345-350 doi:10.4103/1305-7456.184163 